\title{
Thin Functional Polymer Films by Electropolymerization
}

\author{
Alex Palma-Cando ${ }^{1,2, * \mathbb{C}}$, Ibeth Rendón-Enríquez ${ }^{3}$, Michael Tausch ${ }^{3, *}$ and Ullrich Scherf ${ }^{2, *}$ \\ 1 School of Chemical Sciences and Engineering, Universidad Yachay Tech, EC100115 Urcuqui, Ecuador \\ 2 Macromolecular Chemistry Group, Bergische Universität Wuppertal, Gaußstraße 20, \\ D-42119 Wuppertal, Germany \\ 3 Department of Chemistry and Chemical Education, Bergische Universität Wuppertal, Gaußstraße 20, \\ D-42119 Wuppertal, Germany \\ * Correspondence: apalma@yachaytech.edu.ec (A.P.-C.); mtausch@uni-wuppertal.de (M.T.); \\ scherf@uni-wuppertal.de (U.S.)
}

Received: 15 July 2019; Accepted: 2 August 2019; Published: 4 August 2019

\begin{abstract}
Intrinsically conducting polymers (ICPs) have been widely utilized in organic electronics, actuators, electrochromic devices, and sensors. Many potential applications demand the formation of thin polymer films, which can be generated by electrochemical polymerization. Electrochemical methods are quite powerful and versatile and can be utilized for investigation of ICPs, both for educational purposes and materials chemistry research. In this study, we show that potentiodynamic and potentiostatic techniques can be utilized for generating and characterizing thin polymer films under the context of educational chemistry research and state-of-the-art polymer research. First, two well-known bifunctional monomers (with only two linking sites) —aniline and bithiophene-and their respective ICPs—-polyaniline (PANI) and polybithiophene (PBTh)—were electrochemically generated and characterized. Tests with simple electrochromic devices based on PANI and PBTh were carried out at different doping levels, where changes in the UV-VIS absorption spectra and color were ascribed to changes in the polymer structures. These experiments may attract students' interest in the electrochemical polymerization of ICPs as doping/dedoping processes can be easily understood from observable color changes to the naked eye, as shown for the two polymers. Second, two new carbazole-based multifunctional monomers (with three or more linking sites)—tris(4-(carbazol-9-yl)phenyl)silanol (TPTCzSiOH) and tris(3,5-di(carbazol-9-yl)phenyl)silanol (TPHxCzSiOH) - were synthesized to produce thin films of cross-linked polymer networks by electropolymerization. These thin polymer films were characterized by electrochemical quartz crystal microbalance (EQCM) experiments and nitrogen sorption, and the results showed a microporous nature with high specific surface areas up to $930 \mathrm{~m}^{2} \mathrm{~g}^{-1}$. PTPHxCzSiOH-modified glassy carbon electrodes showed an enhanced electrochemical response to nitrobenzene as prototypical nitroaromatic compound compared to unmodified glassy carbon electrodes.
\end{abstract}

Keywords: electropolymerization; thin films; electrochromic devices; microporosity; polymer networks; nitrobenzene detection

\section{Introduction}

Since the dawn of the intrinsically conducting polymers (ICPs) in the late 1970s [1,2], electrochemistry has been a powerful tool, not only for synthesis of polymer films but also for in situ characterization of (semi)conducting materials [3,4]. Electrochemical generation of ICPs is based mainly on the oxidative condensation of different aromatic heterocycles and derivatives through the formation of radical cations [5]. Pyrrole, aniline, thiophene, and carbazole are among the simplest molecules that can be electrochemically polymerized due to their inherent low oxidation potential [6]. Corresponding electrosynthesized ICPs have shown potential applications in electrocatalysis, batteries, capacitors, 
sensors, biosensors, organic light-emitting diodes, organic solar cells, and electrochromic devices [7]. The principle of the last application, i.e., electrochromism, could be in fact an interesting and innovative approach to be used in undergraduate and graduate classes [8,9]. Explanation of the electrochemical doping/dedoping processes of ICPs can be easily managed by applying different potentials to polymer films, resulting in color changes of the deposits via a suited modification of their chemical and electronic structures [10-14]. We have previously reported electrochemical polymerization of three different monomers-4,7-dithienyl-2,1,3-benzothiadiazole, 3,4-ethilendioxythiophene, and pyrrole-using low-cost potentiostats $[15,16]$. Electrochromism of the synthesized polymer films could be easily demonstrated by fabrication of electrochromic windows. These optoelectronic devices showed a clear change in UV-VIS spectra and color when positive or negative potentials were applied. The presented methodology is well suited for the development of experiments in undergraduate and graduate education for demonstrating and explaining electrochromicity.

Electrochemical polymerization of bifunctional monomers (with only two linkable sites) results mainly in the formation of linear, 1D conducting polymer films that have unique advantages over inorganic semiconductors, such as one-step synthesis, thin film deposition, light weight, and low cost $[17,18]$. However, the formed conjugated polymer chains are usually twisted and entangled, leading to a disordered solid-state structure that might result in lower performance in applications where high order is required (e.g., organic electronics). On this ground, over the past years, electrochemical generation of polymer films has been intensively studied, starting from multifunctional monomers (with three or more linkable sites) [19-23]. This methodology usually leads to the formation of films with a 3D network structure that not only maintains all advantages of 1D polymer films but also shows a more robust electronic structure, often accompanied by the occurrence of inherent microporosity with high surface area values [24-26]. Our group has previously synthesized different multifunctional monomers (with up to eight linkable sites) with different cores and linkers that allow the establishment of reliable structure-property relationships between the number of functionalities and the specific surface area of the corresponding electrochemically generated microporous polymer networks (MPNs) [27,28]. Semiconductivity and high surface areas of $>2000 \mathrm{~m}^{2} \mathrm{~g}^{-1}$, in some cases, for these microporous, electron-rich polymer films allowed us to explore their potential applications as electrochemical or fluorescence sensors for nitroaromatic explosives that showed an improved sensitivity by increasing the number of available active sites for molecular interaction [29,30]. In the context of the results of this report, Zhang et al. recently reviewed the electrochemical generation of polymer films using bifunctional or multifunctional monomers and their potential applications [31]. Our study tries to link educational chemistry and materials chemistry, both dealing with the electropolymerization of bi- or higher-functional monomers into functional polymer films.

In this study, we present the electrochemical polymerization of two well-known bifunctional monomers - aniline and bithiophene-in the context of educational chemistry research (see Scheme 1). Electrochemical and spectrophotometric characterization was carried out for the prepared polymer films. Construction of electrochromic windows based on polyaniline (PANI) and polybithiophene (PBTh) was carried out using a very simple setup. At different doping levels, changes in their UV-VIS absorption spectra and color (green-blue-yellow for PANI and pink-blue for PBTh) were observed, which were ascribed to changes in the polymer structures. On the other hand, two new carbazole-based multifunctional monomers-tris(4-(carbazol-9-yl)phenyl)silanol (TPTCzSiOH) and tris(3,5-di(carbazol-9-yl)phenyl)silanol (TPHxCzSiOH) (see Scheme 1)—were electropolymerized into cross-linked, microporous, functional polymer films as an example for the current topic of materials chemistry. Moreover, the electrochemical formation of microporous thin films from multifunctional carbazole monomers was followed up with the electrochemical quartz crystal microbalance (EQCM) method. High specific surface areas $\left(\mathrm{S}_{\mathrm{BET}}\right)$ for both films were determined, with PTPHxCzSiOH films showing a $\mathrm{S}_{\mathrm{BET}}$ of $930 \mathrm{~m}^{2} \mathrm{~g}^{-1}$. PTPHxCzSiOH-modified glassy carbon (GC) electrodes showed improved electrochemical detection ability for nitrobenzene as prototypical nitroaromatic analyte compared to bare GC electrode response. Thus, the study merges electropolymerization research in 
two areas by reporting original results (i) on the adaptation of electrochemical ICP synthesis setup and characterization methods for educational chemistry needs and for a presentation of structure-properties relationship in classroom experiments and (ii) on the electrochemical generation of microporous polymer films, starting from two novel multifunctional monomers.

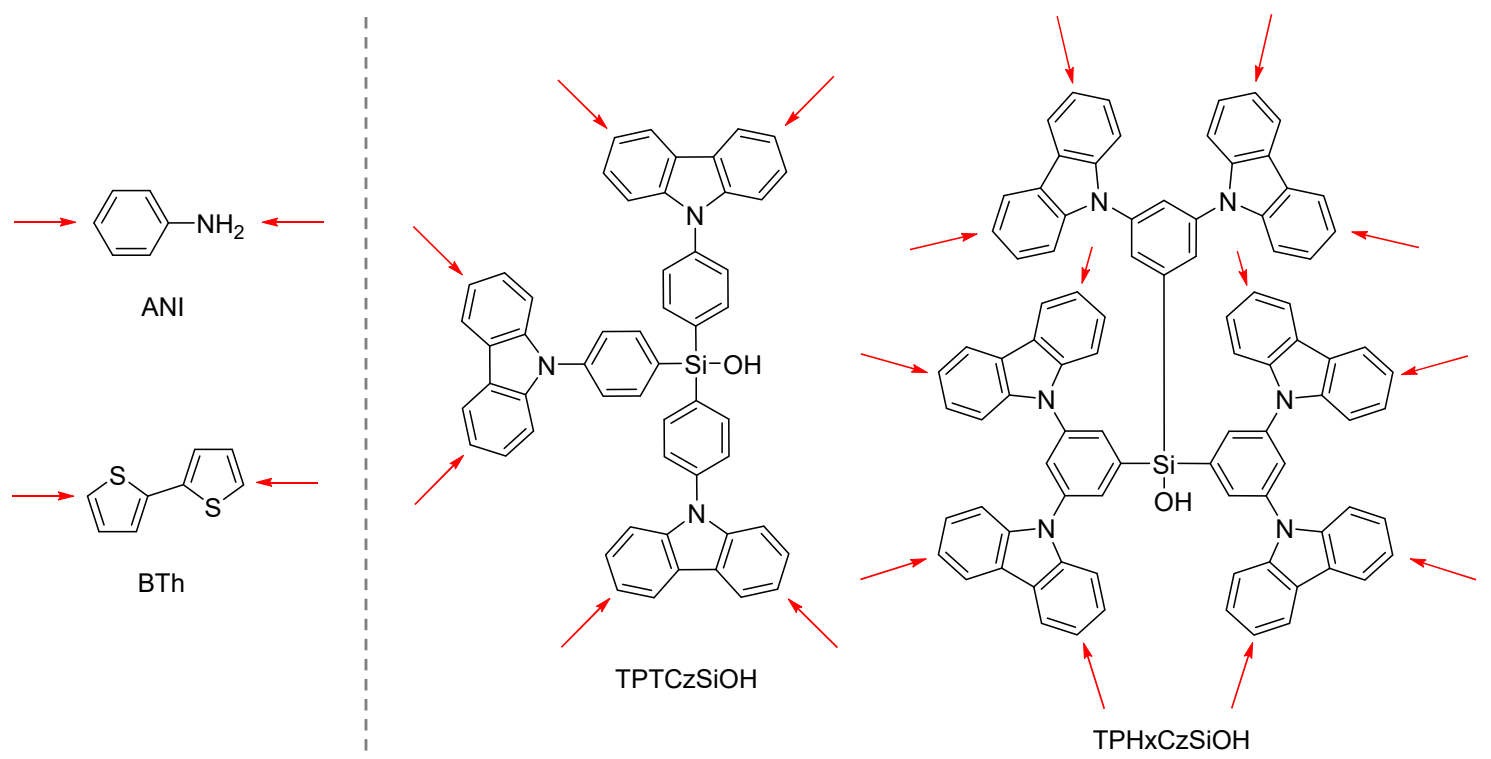

Scheme 1. Chemical structures of the electropolymerized bifunctional (left) and multifunctional (right) monomers. The arrows show the available linking sites on each molecule.

\section{Materials and Methods}

\subsection{Construction of the Electrochromic Devices Based on 1D Polymer Films for Educational Chemistry Purposes}

Electrodeposition of PANI was performed in an aqueous $0.4 \mathrm{M}$ aniline solution with $0.5 \mathrm{M}$

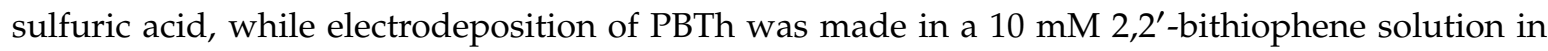
acetonitrile $(\mathrm{MeCN})$ with $0.1 \mathrm{M}$ of tetrabutylammonium perchlorate (TBAP). Fluorine-doped tin oxide $(\mathrm{FTO})$ electrodes $(3.5 \mathrm{~cm} \times 3.5 \mathrm{~cm})$ were used as working electrodes $(\mathrm{WE})$, and stainless-steel plates $(3.5 \mathrm{~cm} \times 3.5 \mathrm{~cm})$ were used as counter electrodes $(\mathrm{CE})$. For potentiostatic electrodeposition of PANI and PBTh films, constant potentials of $0.7 \mathrm{~V}$ vs. $\mathrm{Ag} / \mathrm{AgCl}$ and $0.85 \mathrm{~V}$ vs. $\mathrm{Ag} / \mathrm{AgNO} \mathrm{Nere}$ applied for $5 \mathrm{~min}$, respectively. The electrolyte solution was prepared in a small brown glass vial using $1 \mathrm{~mL}$ of propylene carbonate (PC), $1.3 \mathrm{~g}$ of poly(ethylene glycol) diacrylate (PDA), $5.5 \mathrm{mg}$ of 2,2-dimethoxy-2-phenylacetopheneone (DMAP), and $0.2 \mathrm{~g}$ of lithium trifluoromethanesulfonate (LITRIF). Subsequently, the mixture was treated for $15 \mathrm{~min}$ in an ultrasound bath. Two drops of this solution were added into the polymer-modified FTO electrode. A second clean FTO was placed on the top with a separation distance between the electrodes of ca. $3 \mathrm{~mm}$. Photopolymerization of PDA was done under illumination with $365 \mathrm{~nm}$ light for $15 \mathrm{~min}$ to generate the gel electrolyte layer. Doping and dedoping potentials were applied between the electrodes to evaluate electrochromism of these devices.

The material safety data sheets should be consulted if appropriate. A short list of hazards for all these chemicals can be found in the Supplementary Material.

\subsection{Electrochemical Synthesis and Response to Nitrobenzene (NB) of Microporous 3D Polymer Films as Current Topic in Materials Chemistry}

Ten milliliters of $0.1 \mathrm{mM}$ solutions of $\mathrm{TPTCzSiOH}$ and $\mathrm{TPHxCzSiOH}$ were placed in a three-electrode cell at $25^{\circ} \mathrm{C}$. Glassy carbon working electrodes were connected to platinum wire counter electrodes. $\mathrm{Ag}^{\circ} / \mathrm{AgNO} 3$ was used as nonaqueous reference electrode (RE). Potentiostatic polymerization of $\mathrm{TPTC} \mathrm{TSiOH}$ and $\mathrm{TPH} \mathrm{C} \mathrm{C} \mathrm{SiOH}$ was attained under inert atmosphere by applying 
a constant polymerization potential of $1.1 \mathrm{~V}$ until an oxidative charge of $0.20 \mathrm{mC}$ was accumulated. After electrochemical dedoping and washing of the deposits with MeCN and methylene chloride, the polymer-modified GC electrodes were placed in $10 \mathrm{~mL}$ of an aqueous solution containing $0.2 \mathrm{M}$ potassium chloride and $0.1 \mathrm{M}$ phosphate buffer under inert atmosphere at $25^{\circ} \mathrm{C}$. An aqueous reference electrode $\left(\mathrm{Ag}^{\circ} / \mathrm{AgCl}\right)$ was used for these tests. Equilibration was achieved by stirring the mixtures for $5 \mathrm{~min}$ followed by applying a prepotential of $0 \mathrm{~V}$ for $30 \mathrm{~s}$. Linear scan voltammograms (LSVs) were registered in the potential range of $0 \mathrm{~V}$ to $-1 \mathrm{~V}$ with a scan rate of $10 \mathrm{mV} \mathrm{s}{ }^{-1}$. For detection of nitroaromatic compounds, aliquots from a $100 \mathrm{M}$ nitrobenzene (NB) stock solution in MeCN were added to the buffered solutions to reach the intended NB concentration $(0.5 \mu \mathrm{M})$.

For additional and detailed information, please see the Supplementary Material.

\section{Results and Discussion}

\subsection{Electrochemical Polymerization of Bifunctional Monomers for a Simple Demonstration of Electrochromic Effects}

The electrochemical polymerization of aniline proceeds via a radical propagation mechanism. The initial step is the oxidation of two molecules of aniline to radical cations. The second step involvs a radical coupling between the N-radical cation and para-carbon radical to form a dimer, which further undergoes proton elimination. Chain propagation involves oxidation of dimer to a dimer N-radical cation and coupling with para-carbon radical to form a trimer after deprotonation. This cascade process leads to deposition of PANI on the surface of an electrode driven by the reduced solubility of the coupling products (see Supplementary Scheme S1). Unlike in other conductive polymers, the heteroatom is directly introduced as a linker atom into the main chain [32]. Using cyclic voltammetry, electrodeposition of PANI was evaluated on the surface of a platinum disc electrode (see Figure 1a). Polymerization under potentiodynamic conditions provided information about the growth of the film. Oxidation of the monomer began at $0.85 \mathrm{~V}$ (red line in Figure 1a), while oxidation of the polymer showed three peaks. Peak I (ca. $0.2 \mathrm{~V}$ ) corresponded to the first step of oxidation of the species $\mathrm{HN}-\mathrm{R}-\mathrm{NH}\left(\mathrm{R}: \mathrm{C}_{6} \mathrm{H}_{4}\right)$ in the main chain to a cation radical or polaron system $\mathrm{HN}-\mathrm{R}-\mathrm{NH}^{+}$. The cation radical was then oxidized, almost at the same potential, to the dication or bipolaron $\mathrm{HN}^{+}=\mathrm{R}=\mathrm{NH}^{+}$. The dication could then be oxidized at a potential that corresponded to the third peak of ca. $0.85 \mathrm{~V}$ [33]. The middle peak in the voltammogram was related to the presence of an intermediate during the electropolymerization of aniline and/or to the formation of cross-linked polyaniline chains [34]. The increase in the current with every next cycle of multisweep cyclic voltammograms (CVs) showed an increase in the polymer thickness as well as in the number of redox-active sites.

The electropolymerization of bithiophene also proceeds via a radical propagation mechanism. The polymerization starts in solution and takes place from a dimer oxidation to a tetramer and so on until deposition of elongated polymer chains (see Supplementary Scheme S2) [5]. Therefore, electrodeposition of polybithiophene (PBTh) films could be accomplished by applying oxidative potentials to a diluted solution of 2,2' -bithiophene (see Figure 1b) [35]. Oxidation of the monomer began at $0.81 \mathrm{~V}$ (red line in Figure 1b). Peak I, around $0.68 \mathrm{~V}$, was assigned to p-doping of the as-prepared polymer chains, which appeared from the second sweep onwards. The two reduction peaks $(0.65 \mathrm{~V}$ and $0.25 \mathrm{~V})$ were assigned to two stable states of partially discharged polymer chains [36]. The generated polymer (polybithiophene) was of high stability as the charging and discharging processes were fully reversible. In other words, the ratio between the negative charge $(\mathrm{Q}-$ discharging process) and the positive charge (Q+ charging process) was around one in each cycle [37-39]. The conducted experiments showed good stability for both polymer films under the applied conditions (see Supplementary Figure S1). 

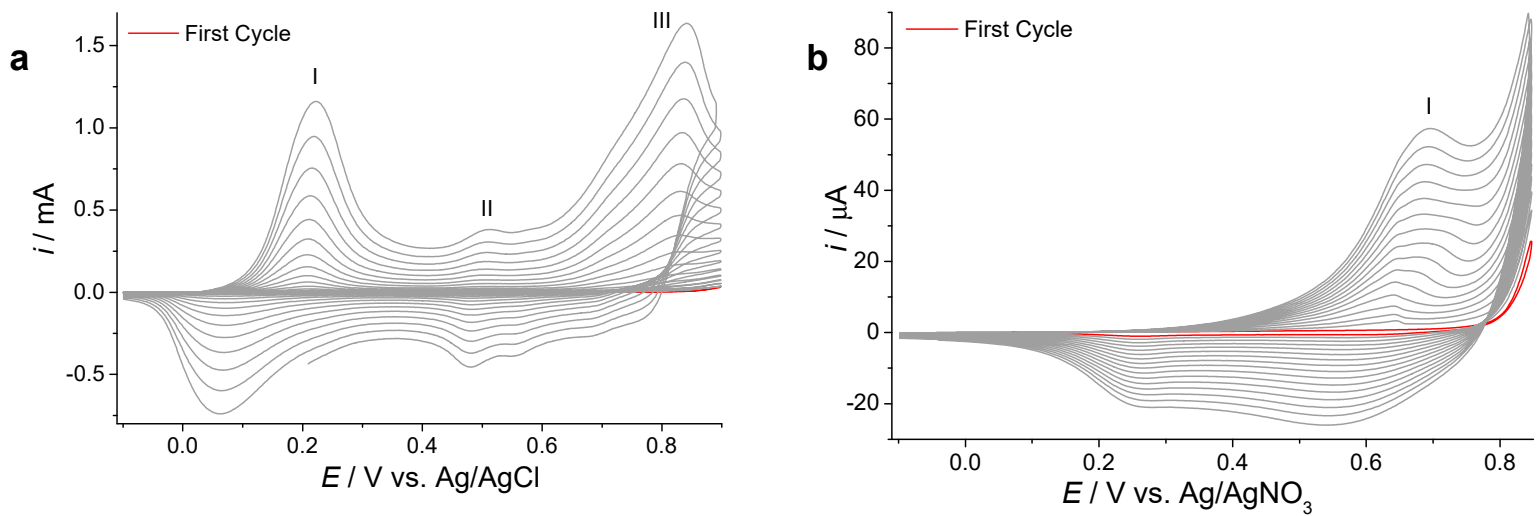

Figure 1. (a) Cyclic voltammograms (CVs) for electropolymerization of $0.4 \mathrm{M}$ aniline in an aqueous $0.5 \mathrm{M}$ sulfuric acid solution at platinum disc electrodes. (b) Cyclic voltammograms for electropolymerization of $2 \mathrm{mM}$ bithiophene and $0.1 \mathrm{M}$ tetrabutylammonium perchlorate solutions in $\mathrm{MeCN}$ at platinum disc electrodes. The voltammograms were recorder from -0.1 to $0.9 \mathrm{~V}$ (polyaniline (PANI)), or $0.85 \mathrm{~V}$ (polybithiophene (PBTh)) with a sweep rate of $0.1 \mathrm{~V} \mathrm{~s}^{-1}$.

Both polymers show a distinct electrochromism behavior, i.e., the film changed color when different redox potentials were applied. In the case of PANI, it is possible to differentiate three chemical and electronic structures-leucoemeraldine, emeraldine, and pernigraniline-all showing different colors and electronic properties (see Scheme 2) [32,40,41].
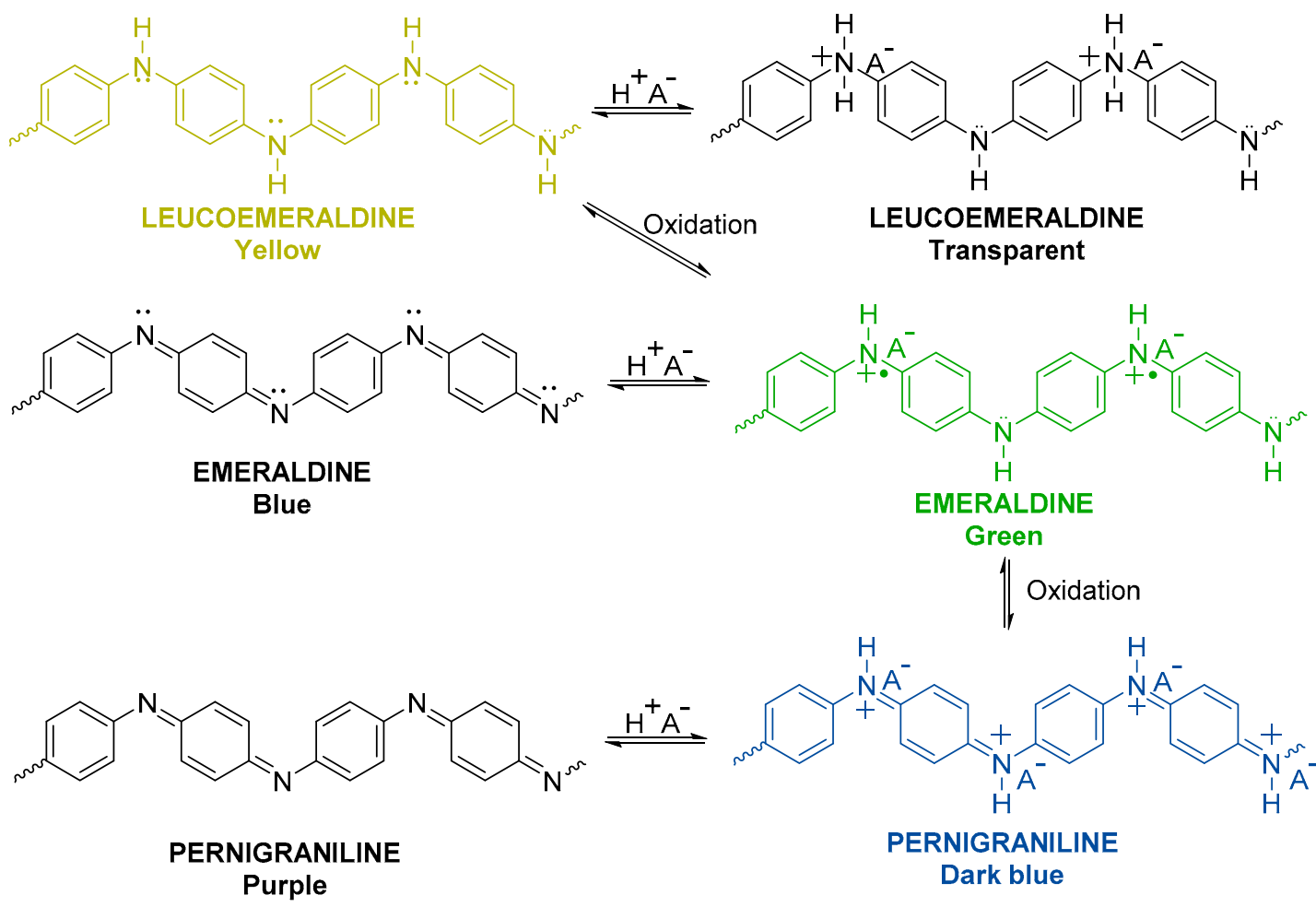

PERNIGRANILINE

Dark blue

Scheme 2. Protonation/deprotonation and redox reactions between the discussed redox states of polyaniline.

In our experiments, UV-VIS absorption spectra were measured for both polymers after different potentials were applied in $0.1 \mathrm{M} \mathrm{KCl}$ aqueous solution (for PANI-modified electrodes) and $0.1 \mathrm{M}$ of tetrabutylammonium perchlorate in MeCN solution (for PBTh-modified electrodes) (see Figure 2). All forms of PANI showed two clear absorption bands; the first one was observed with a maximum at about $350 \mathrm{~nm}$ and a shoulder around $400 \mathrm{~nm}$. According to the literature, this band was related to 
a $\pi-\pi^{*}$ transition [41]. The second band arose from 500 to $1000 \mathrm{~nm}$, which was related to the formation of polarons or radical cations (polaron band). The applications of low potentials, ca. $-0.2 \mathrm{~V}$, led to the formation of the leucoemeraldine form of PANI. Starting from $-0.2 \mathrm{~V}$, as the applied potential increased up to $0.2 \mathrm{~V}$, the absorption maximum at around $350 \mathrm{~nm}$ also increased, the shoulder at ca. $400 \mathrm{~nm}$ decreased, and there was also a bathochromic shift for both peaks. Additionally, the polaron band absorption increased with the rise of the applied potential to PANI-modified electrode adopting the emeraldine structure. The peak at $350 \mathrm{~nm}$ continuously decreased with increasing applied potential up to $0.6 \mathrm{~V}$. The polaron band also showed a hypochromic shift. By increasing the applied potential up to $0.9 \mathrm{~V}$, the polaron band further shifted hypochromically and started to decrease with the formation of the pernigraniline structure [40]. A PBTh film showed an absorption maximum around $500 \mathrm{~nm}$ with two shoulders at ca. 350 and $400 \mathrm{~nm}$. This band was related to a $\pi-\pi^{*}$ transition in the polymer chain, which decreased as the applied potential increased [42]. There was a second broad band with a maximum at about $700 \mathrm{~nm}$ ascribed to an excitation of polarons or radical cations (polaron band). The intensity of the polaron band increased as the applied potential was increased. The polaronic state appeared at applied potentials between 0.2 and $0.4 \mathrm{~V}$. The application of a potential of $0.6 \mathrm{~V}$ led to the formation of bipolaronic structures [42]. PBTh film could be dedoped into the neutral state when a negative potential in the range of -0.6 to $-0.2 \mathrm{~V}$ was applied.
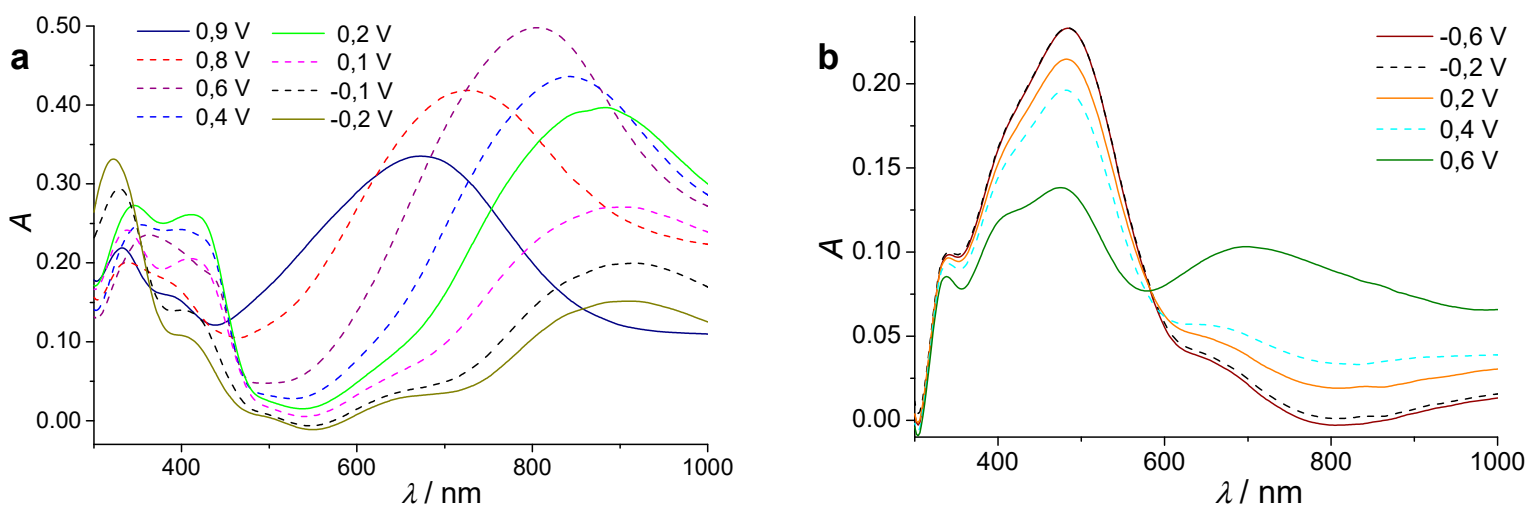

Figure 2. UV-VIS absorption spectra of (a) PANI and (b) PBTh deposited on fluorine-doped tin oxide (FTO) at different doping levels. Polymer films were placed in a $0.1 \mathrm{M} \mathrm{KCl}$ aqueous solution (for PANI-modified electrode) and 0.1 M tetrabutylammonium perchlorate solutions in MeCN (for PBTh-modified electrode) followed by application of different potentials for $10 \mathrm{~s}$.

Electrochromism of these thin polymer films can be exploited for teaching purposes by building low-cost electrochromic devices made of electropolymerized active layers. These optoelectronic devices can easily demonstrate correlation between chemical structure and doping level of polymers at a certain potential by visual color changes. Herein, a solution of DMAP (0.02 M) and LITRIF (0.10 M) in PC/PDA (1:1) as electrolyte precursor was prepared [43], and two drops of this solution were placed onto a FTO electrode with an electrodeposited thin polymer film. A second FTO plate was used as counter electrode. The photopolymerization of PDA under illumination with $365 \mathrm{~nm}$ light kept the two electrodes together by formation of a gel electrolyte. Different potentials were applied between the electrodes, leading to changes in the color of the devices and their absorption spectra (see Figure 3). The potential was applied using a low-cost potentiostat without a reference electrode [15,16]. After the construction of the device, PANI films remained partially oxidized on its polaronic state, which corresponded to the emeraldine form (see Figure 3a). The polymer can suffer further oxidation to a pernigraniline form on its bipolaronic state and take a blue color. If a reductive potential is applied, the polymer reaches its neutral state or leucoemeraldine form with a yellow color. PBTh films remained partially oxidized on its polaronic state after the construction of the device, taking a light pink color (see Figure 3b). The polymer can suffer further oxidation to its bipolaronic state with a green color. If a reductive potential is applied, PBTh reaches its neutral form and changes color to dark pink. 

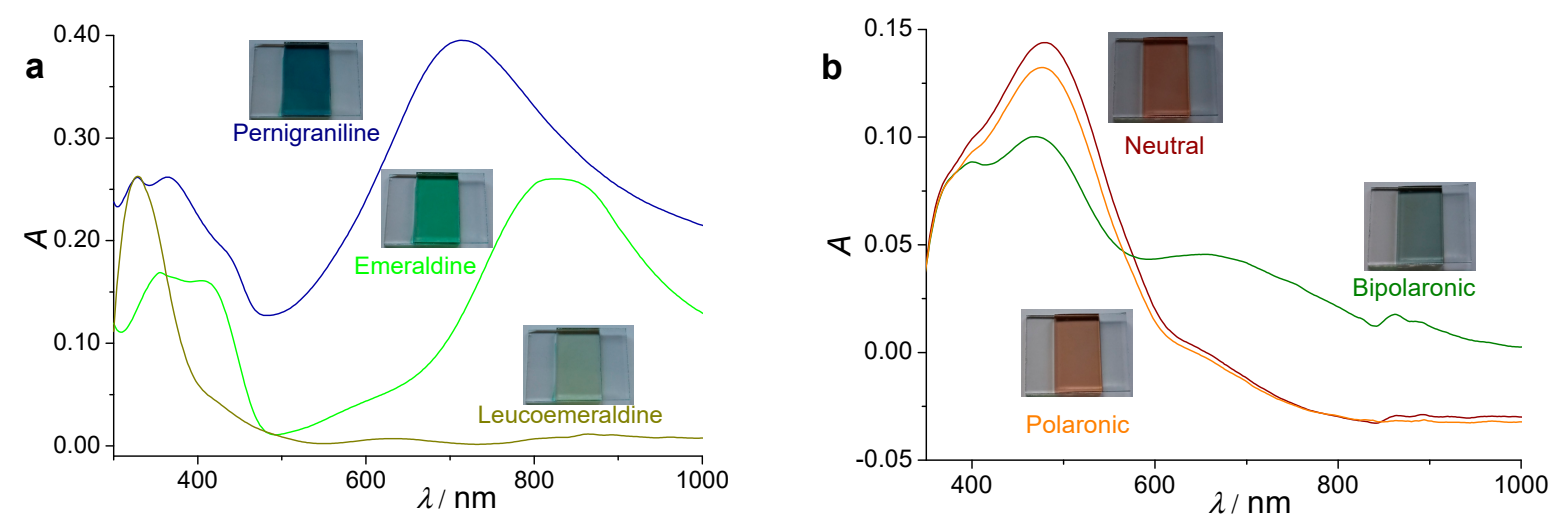

Figure 3. Absorption spectra and photographic images of electrochromic devices based on (a) PANI and (b) PBTh at different doped levels.

3.2. Electrochemical Polymerization of Multifunctional Monomers as a Current Topic for the Electrodeposition of Functional Films

The silicon-centered tri- or hexafunctional monomers were prepared according to previously reported procedures. Synthetic details and structural characterization of both monomers are presented in the Supplementary Material. Partial coupling (trisubstitution) of $\mathrm{SiCl}_{4}$ with 9-(4-bromophenyl)carbazole or 5-bromo-1,3-di(carbazol-9-yl)benzene was realized with ca. 30\% yield to give TPTCzSiOH or TPHxCzSiOH monomers, respectively.

MPN film generation was achieved by electrochemical oxidative coupling of both carbazole derivatives. For these experiments, $0.1 \mathrm{mM}$ solutions of the monomers were prepared in $\mathrm{MeCN} /$ methylene chloride (1:4). Tetrabutylammonium perchlorate (TBAP) was added to the solutions as supporting electrolyte with a concentration of $0.1 \mathrm{M}$. A conventional three-electrode cell was set up with platinum disc as working electrode, platinum wire as counter electrode, and $\mathrm{Ag} / \mathrm{Ag}^{+}$as reference electrode. Figure 4 shows the first anodic voltammograms up to $1.1 \mathrm{~V}$ at a sweep rate of $0.10 \mathrm{~V} \mathrm{~s}^{-1}$ for electropolymerization of TPTCzSiOH (black line) and TPHxCzSiOH (red line) on platinum disc electrodes. First oxidation peaks were attributed to a cascade of oxidation of carbazoles into radical cations followed by coupling and deprotonation of the intermediates into 3,3'-dicarbazole dimers $[44,45]$. TPHxCzSiOH oxidation current peak was higher than TPTCzSiOH oxidation current peak in line with double the amount of electroactive groups. Higher oxidation potential was needed for the hexacarbazolyl monomer compared to the tricarbazolyl monomer, which could be related to the sterically demanding di(carbazol-9-yl)-benzene linker, resulting in a higher carbazolyl-phenyl distortion. Twenty successive CVs were recorded from -1.0 to $1.1 \mathrm{~V}$ at a sweep rate of $0.10 \mathrm{~V} \mathrm{~s}^{-1}$ for polymerization of TPTCzSiOH and TPHxCzSiOH (see Supplementary Figure S2). Successive sweeping prompted a gradually increased current, indicating a cumulative polymer deposit on the electrode. In both cases, two reversible peaks were clearly shown in potentials from 0.4 to $1.1 \mathrm{~V}$. These waves could be related to the charging/discharging of the MPN films by formation of radical cations (polarons) or dications (bipolarons) [46]. MPN-modified platinum disc electrodes were studied in monomer-free solutions by recording CVs at different sweep rates (see Supplementary Figure S3). A linear relationship was shown between anodic/cathodic peak current and sweep rate, which is characteristic of well-adhered thin deposits with absence of diffusional limitations [47]. 


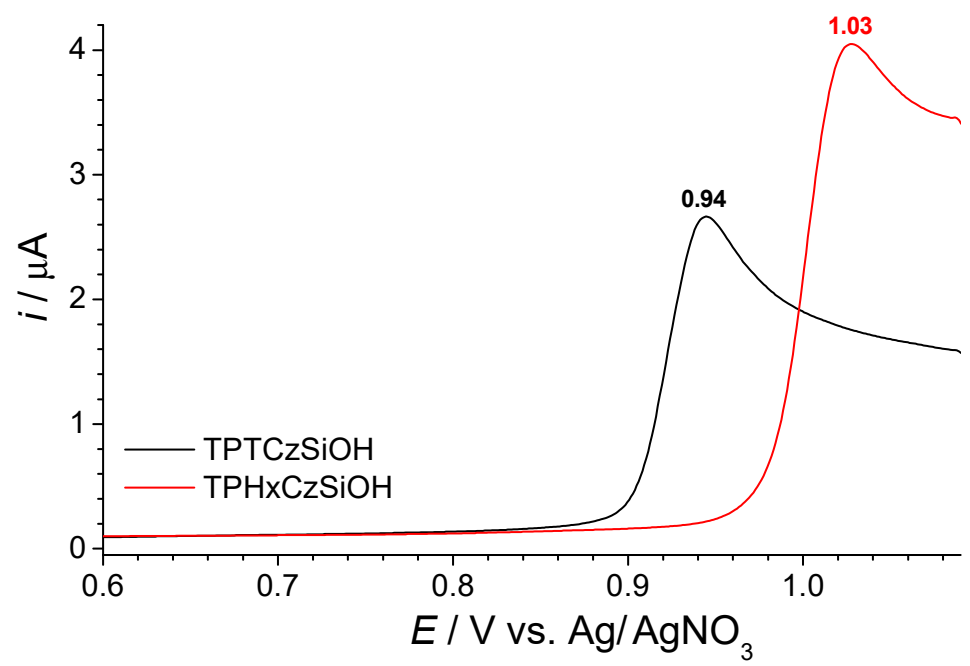

Figure 4. First anodic sweep voltammograms for $0.1 \mathrm{mM}$ of tris(4-(carbazol-9-yl)phenyl)silanol (TPTCzSiOH) (black line) or tris(3,5-di(carbazol-9-yl)phenyl)silanol (TPHxCzSiOH) (red line) and $0.1 \mathrm{M}$ tetrabutylammonium perchlorate solutions in $\mathrm{MeCN} /$ methylene chloride (1:4) at platinum disc electrodes. The voltammograms were recorded from 0 to $1.1 \mathrm{~V}$ with a sweep rate of $0.10 \mathrm{~V} \mathrm{~s}^{-1}$.

EQCM gives additional information regarding gain and loss of material on top of an electrode by determination of frequency changes [48]. The frequency variations (f) of a quartz crystal resonator is associated with the mass change by the Sauerbrey relation [49]. Ten cyclic voltammograms were recorded for TPTCzSiOH and $\mathrm{TPHxCzSiOH}$ electropolymerization at platinum/quartz electrodes under identical settings as previously outlined (see Figure 5a,d). During the first anodic sweep, onset frequencies decrease clearly corresponded to respective oxidation onset potentials of TPTCzSiOH (ca. $0.9 \mathrm{~V}$ ) and TPHxCzSiOH (ca. $1.0 \mathrm{~V}$ ), where polymer deposition started. Progressive polymer film formation led to continuously decrease frequency values. This phenomenon can be better appreciated in a mass vs. time plot (see Figure $5 b, e$ ). A constantly increasing mass was determined for a possible layer-by-layer film growth. Peaks observed at the beginning of each mass step were related to the reversible counteranion uptake and release in the charging/discharging process of the electroactive polymer films. This reversible process was observed well by recording cyclic voltammograms coupled to QCM for polymer deposits in monomer-free solutions $(0.1 \mathrm{M}$ tetrabutylammonium perchlorate in $\mathrm{MeCN}$ ) (see Figure $5 \mathrm{c}, \mathrm{f})$. Polymer oxidation (p-doping) process was accompanied with insertion of perchlorate counteranions into the deposited matrix, resulting in a progressive frequency decrease (e.g., mass increase). Subsequent polymer reduction (dedoping) corresponded to a release of perchlorate counter anions from the polymer matrix into the solution, resulting in frequency increase (e.g., mass decrease). Frequency hysteresis and slight mass growth at the switching potential of the cycle might be connected to a restricted counterion mobility and to a partial release of trapped perchlorate counterions, respectively [50]. 

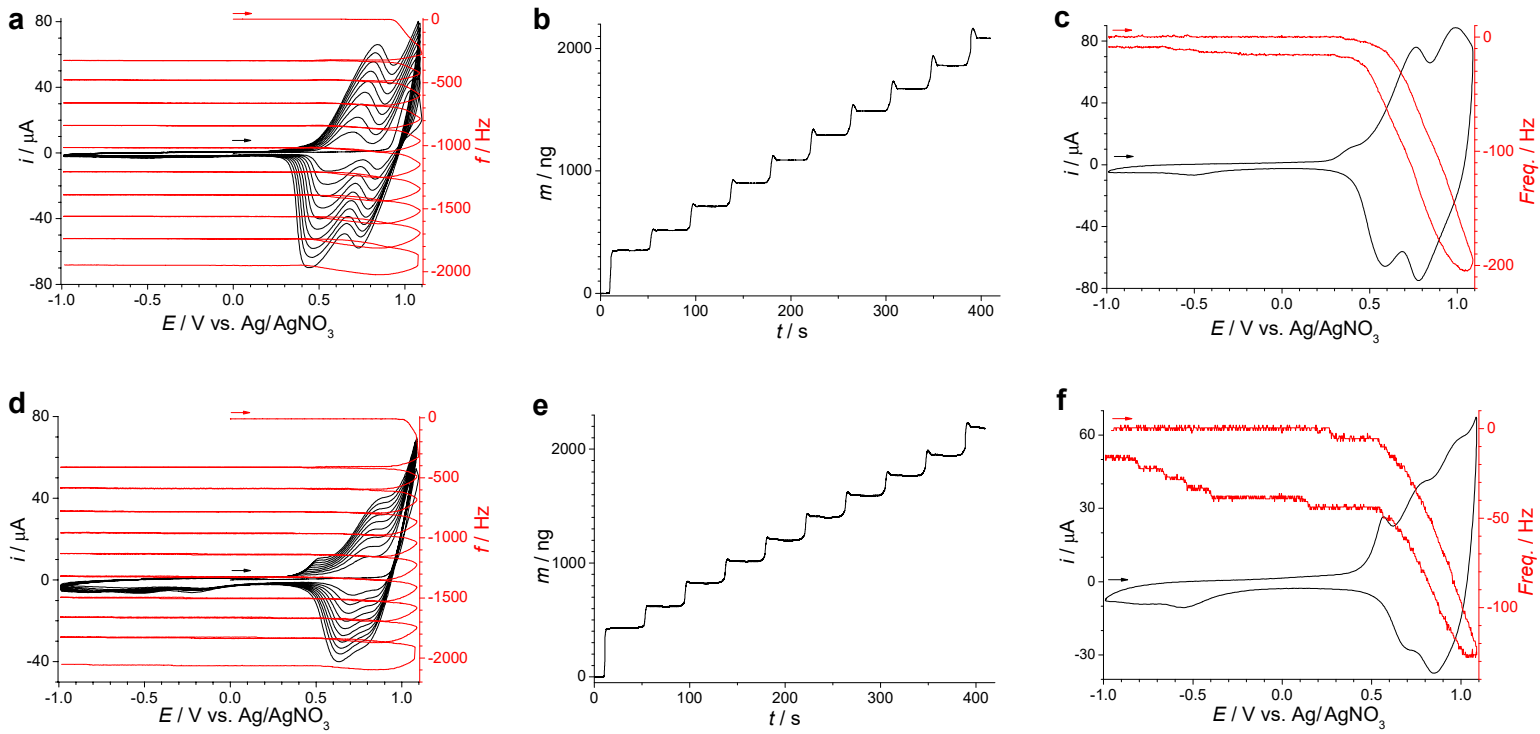

Figure 5. Ten successive CVs (black lines) and corresponding quartz microbalance frequency response (red lines) in the electropolymerization at platinum/quartz working electrodes of $0.1 \mathrm{mM}$ solutions of (a) TPTCzSiOH and (d) $\mathrm{TPHxCzSiOH}$ and $0.1 \mathrm{M}$ tetrabutylammonium perchlorate in $\mathrm{MeCN} /$ methylene chloride (1:4). Mass accumulation during electropolymerization of (b) TPTCzSiOH and (e) TPHxCzSiOH, calculated by applying the Sauerbrey equation. CVs (black lines) and corresponding quartz microbalance frequency response (red lines) for thin films of (c) PTPTCzSiOH and (f) $\mathrm{PTPHxCzSiOH}$ on platinum/quartz electrodes in $0.1 \mathrm{M}$ tetrabutylammonium perchlorate in $\mathrm{MeCN}$ solutions. All CVs were registered from -1.0 to $1.1 \mathrm{~V}$ with a sweep rate of $0.10 \mathrm{~V} \mathrm{~s}^{-1}$.

Morphology studies of thin MPN films were carried out by tapping-mode atomic force microscopy (AFM) analysis (see Supplementary Figure S4 and Table S1). These films showed average surface roughness $\left(\mathrm{R}_{\mathrm{q}}\right) /$ thickness of $8.0 \mathrm{~nm} / 45 \mathrm{~nm}$ for PTPTCzSiOH and $6.3 \mathrm{~nm} / 50 \mathrm{~nm}$ for PTPHxCzSiOH, respectively. Specific surface areas of the porous films were calculated from the polymer's krypton adsorption isotherms in the relative pressure range of 0-0.6 at $77 \mathrm{~K}$ (see Figure 6a). Thick, free-standing films were obtained on indium tin oxide (ITO) electrodes by potentiostatic electropolymerization applying $1.0 \mathrm{~V}$ (in $0.5 \mathrm{mM}$ TPTCzSiOH solution) and $1.1 \mathrm{~V}$ (in $0.5 \mathrm{mM} \mathrm{TPHxCzSiOH}$ solution) for $20 \mathrm{~min}$. High gas adsorption at low relative pressure $(<0.1)$ indicates microporosity of the polymer films [51]. Specific surface areas $\left(\mathrm{S}_{\mathrm{BET}}\right)$ of $165 \mathrm{~m}^{2} \mathrm{~g}^{-1}$ for PTPTCzSiOH films and $930 \mathrm{~m}^{2} \mathrm{~g}^{-1}$ for PTPHxCzSiOH films were computed using the Brunauer-Emmett-Teller (BET) equation. Higher surface areas are usually expected for higher monomer functionality due to an increased cross-linking density and rigidity, resulting in an increased permanent microporosity [25]. For comparison purposes, chemical oxidative polymerization of both monomers was carried out with iron(III) chloride, resulting in the formation of powdery polymers in good yields $(>85 \%)$. These materials showed good thermal (see Supplementary Figure S5) and chemical resistance and strong blue photoluminescence (see Supplementary Figure S6). Nitrogen sorption isotherms at $77 \mathrm{~K}$ were recorded for these chemically made bulk polymers (see Supplementary Figure S7), showing similar trends in the adsorption isotherms for films and bulk materials. Slightly reduced specific surface areas were usually found for the electrochemically made polymer films $\left(165 \mathrm{~m}^{2} \mathrm{~g}^{-1}\right.$ for PTPTCzSiOH films and $930 \mathrm{~m}^{2} \mathrm{~g}^{-1}$ for PTPHxCzSiOH films) compared to chemically made powdery materials $\left(405 \mathrm{~m}^{2} \mathrm{~g}^{-1}\right.$ for PTPTCzSiOH powder and $1285 \mathrm{~m}^{2} \mathrm{~g}^{-1}$ for PTPHxCzSiOH powder). This phenomenon may be ascribed to a reduced cross-linking density during electropolymerization compared to the $\mathrm{FeCl}_{3}$-mediated condensation. Electrochemical oxidative coupling of carbazoles leads mainly to the formation of 3,3'-dimers, while chemical oxidative coupling might also form additional 7,7'-dicarbazole linkages [52]. 

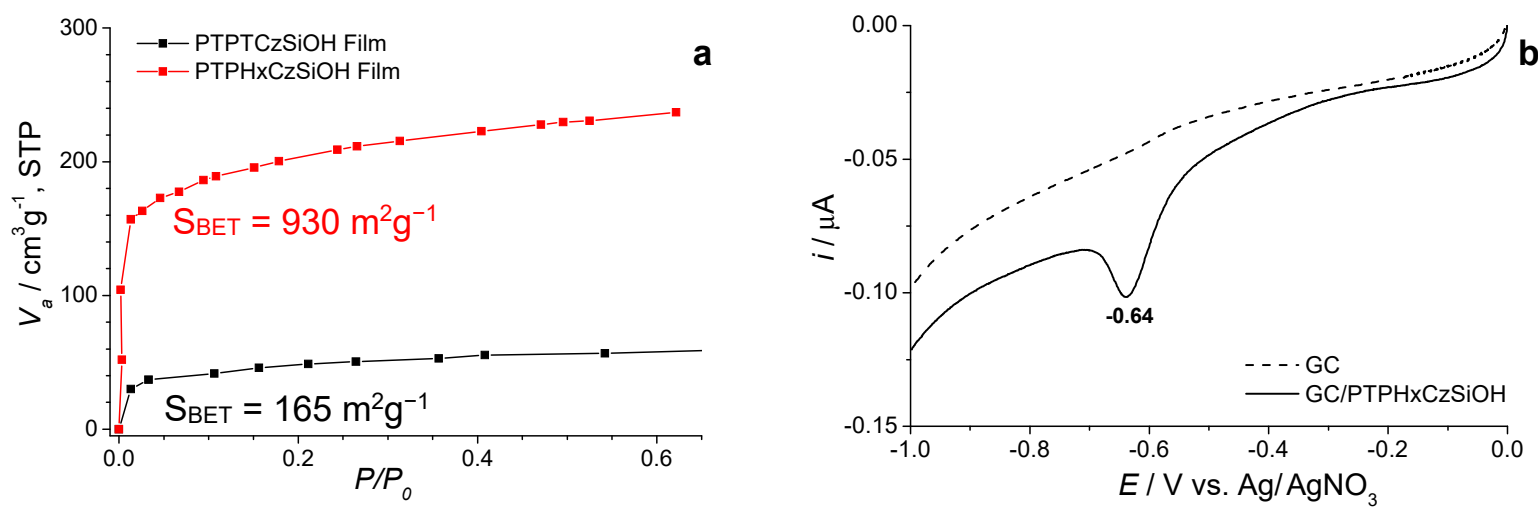

Figure 6. (a) Adsorption isotherms of electrochemically produced polymer films using krypton gas. Specific surface areas were obtained by applying the Brunauer-Emmett-Teller (BET) equation to the krypton gas adsorption isotherms (mean value of three measurements). (b) Linear scan voltammograms for the detection of $0.5 \mu \mathrm{M}$ nitrobenzene at bare (dashed line) and PTPHxCzSiOH-modified (solid line) glassy carbon electrodes in aqueous, buffered solutions. These voltammograms were recorded with a sweep rate of $0.01 \mathrm{~V} \mathrm{~s}^{-1}$.

Finally, the electrochemical response of nitrobenzene (NB) as prototypical nitroaromatic analyte was demonstrated on GC electrodes coated with microporous PTPHxCzSiOH deposits. Microporous polymer films were obtained by potentiostatic oxidative polymerization of $0.1 \mathrm{mM} \mathrm{TPHxCzSiOH}$ in $\mathrm{MeCN} /$ methylene chloride (1:4) solutions. The films were subsequently washed and transferred into an aqueous environment. Figure $6 \mathrm{~b}$ shows linear scan voltammograms (LSVs) for the reduction of $0.5 \mu \mathrm{M} \mathrm{NB}$ on bare glassy carbon and PTPHxCzSiOH-modified electrodes. These LSVs were registered in aqueous, buffered solutions ( $\mathrm{pH}$ 7.4) in a potential window from 0 to $-1.0 \mathrm{~V}$ with a sweep rate of $0.01 \mathrm{~V} \mathrm{~s}^{-1}$. A single wave occurred at a potential of $-0.64 \mathrm{~V}$, which corresponded to the reduction of nitro into hydroxylamine groups as a four-electron reduction of nitrobenzene [53]. In contrast, no detectable reduction peak was observed for the reduction of $0.5 \mu \mathrm{M} \mathrm{NB}$ on bare GC electrodes, thus demonstrating the increased detection of the porous film-modified electrodes. This observation can be explained by increased interfacial interactions between the electron-rich microporous polymers and the electron-poor nitroaromatic analytes [54].

\section{Conclusions}

Two different application scenarios were outlined for electrochemically deposited thin polymer films. Electrochemically generated polyaniline or polybithiophene films (made from bifunctional monomers) led to the formation of 1D polymer chains. Films of these polymers showed clear color changes at different doping levels. Electrochromicity experiments with these films can support teaching classes related to the electroactivity of organic semiconductors. TPTCzSiOH and $\mathrm{TPHxCzSiOH}$ (multifunctional monomers) were utilized for the electrodeposition of microporous polymer films as an example of current polymer electrochemistry research. High intrinsic surface areas of these electron-rich polymer films motivated us to successfully use them for the detection of electron-poor nitroaromatic analytes in micromolar levels.

Supplementary Materials: The following is available online at http://www.mdpi.com/2079-4991/9/8/1125/s1, Synthetic details, electrochemical, optical, thermal, morphological, and porosity characterization of the polymer materials. Scheme S1: Electrochemical polymerization steps of aniline condensation during deposition of PANI films, Scheme S2: Electrochemical polymerization steps of bithiophene during deposition of PBTh films, Figure S1: Cathodic to anodic charging/discharging ratios for 30 sweeps during deposition of PANI and PBTh onto platinum disc electrodes, Figure S2: Polymerization CVs of TPTCzSiOH and TPHxCzSiOH monomers at platinum disc electrodes, Figure S3: CVs in monomer-free solution and linear dependence of peaks current and sweep rate for PTPTCzSiOH and PTPHxCzSiOH deposits, Figure S4: AFM images of thin, microporous polymer films on ITO, Table S1: Average roughness/thicknesses values of electrogenerated thin porous polymer films on ITO, Figure S5: TGA plots of the corresponding chemically synthesized, bulk polymer networks, Figure S6: UV-VIS 
and photoluminescence spectra of the bulk polymer networks, Figure S7: Nitrogen gas sorption isotherms and specific surface areas of bulk polymer networks.

Author Contributions: U.S., M.T. and A.P.-C. conceived and designed the experiments. A.P.-C. and I.R.-E. performed the experiments. All authors analyzed the data. A.P.-C. wrote the paper. All authors discussed the results and reviewed the paper.

Funding: Part of this research was funded by Photo-LeNa (Photoprozesse in der Lehre der Naturwissenschften), grant number TA 228/4-1.

Acknowledgments: We thank Thomas Riedl for the access to the profilometer and Silvia Adamczyk for the AFM measurements. We thank the German Research Foundation (DFG) for funding the research project TA 228/4-1 Photo-LeNa (Photoprozesse in der Lehre der Naturwissenschften). A. Palma-Cando thanks the German Academic Exchange Service (DAAD) for granting him a Ph.D. scholarship.

Conflicts of Interest: The authors declare no conflict of interest.

\section{References}

1. Shirakawa, H.; Louis, E.J.; MacDiarmid, A.G.; Chiang, C.K.; Heeger, A.J. Synthesis of electrically conducting organic polymers: Halogen derivatives of polyacetylene, $(\mathrm{CH})$ x. J. Chem. Soc. Chem. Commun. 1977, 16, 578-580. [CrossRef]

2. Chiang, C.K.; Fincher, C.R., Jr.; Park, Y.W.; Heeger, A.J.; Shirakawa, H.; Louis, E.J.; Gau, S.C.; MacDiarmid, A.G. Electrical Conductivity in Doped Polyacetylene. Phys. Rev. Lett. 1977, 39, 1098-1101. [CrossRef]

3. Bidan, G. Electropolymerized Films of $\pi$-Conjugated Polymers. A Tool for Surface Functionalization: A Brief Historical Evolution and Recent Trends. In Electropolymerization: Concepts, Materials and Applications; Cosnier, S., Karyakin, A., Eds.; Wiley-VCH: Weinheim, Germany, 2010.

4. Palma-Cando, A.; Frontana-Uribe, B.; Varela-Guerrero, V. Relationship Between Charge Transfer Diffusion Coefficients and Doping Level for Electrogenerated Thin PEDOT Films on ITO. Bionatura 2019. [CrossRef]

5. Heinze, J.; Frontana-Uribe, B.A.; Ludwigs, S. Electrochemistry of Conducting Polymers-Persistent Models and New Concepts. Chem. Rev. 2010, 110, 4724-4771. [CrossRef] [PubMed]

6. Bunting, R.K.; Swarat, K.; Yan, D.; Finello, D. Synthesis and Characterization of a Conducting Polymer: An Electrochemical Experiment for General Chemistry. J. Chem. Educ. 1997, 74, 421. [CrossRef]

7. Ibanez, J.G.; Rincón, M.E.; Gutierrez-Granados, S.; Chahma, M.h.; Jaramillo-Quintero, O.A.; Frontana-Uribe, B.A. Conducting Polymers in the Fields of Energy, Environmental Remediation, and Chemical-Chiral Sensors. Chem. Rev. 2018, 118, 4731-4816. [CrossRef] [PubMed]

8. Sherman, B.C.; Euler, W.B.; Force, R.R. The Modern Student Laboratory: Polyaniline-A Conducting Polymer: Electrochemical Synthesis and Electrochromic Properties. J. Chem. Educ. 1994, 71, A94. [CrossRef]

9. Schmidt, D.J.; Pridgen, E.M.; Hammond, P.T.; Love, J.C. Layer-by-Layer Assembly of a pH-Responsive and Electrochromic Thin Film. J. Chem. Educ. 2010, 87, 208-211. [CrossRef]

10. Ibanez, J.G.; Puente-Caballero, R.; Torres-Perez, J.; Bustos, D.; Carmona-Orbezo, A.; Sevilla, F.B. An Inexpensive Device for Studying Electrochromism. J. Chem. Educ. 2012, 89, 1205-1207. [CrossRef]

11. Kerszulis, J.A.; Amb, C.M.; Dyer, A.L.; Reynolds, J.R. Follow the Yellow Brick Road: Structural Optimization of Vibrant Yellow-to-Transmissive Electrochromic Conjugated Polymers. Macromolecules 2014, 47, 5462-5469. [CrossRef]

12. Argun, A.A.; Aubert, P.-H.; Thompson, B.C.; Schwendeman, I.; Gaupp, C.L.; Hwang, J.; Pinto, N.J.; Tanner, D.B.; MacDiarmid, A.G.; Reynolds, J.R. Multicolored Electrochromism in Polymers: Structures and Devices. Chem. Mater. 2004, 16, 4401-4412. [CrossRef]

13. Reeves, B.D.; Thompson, B.C.; Abboud, K.A.; Smart, B.E.; Reynolds, J.R. Dual Cathodically and Anodically Coloring Electrochromic Polymer Based on a Spiro Bipropylenedioxythiophene [(Poly(spiroBiProDOT)]. Adv. Mater. 2002, 14, 717-719. [CrossRef]

14. Kumar, A.; Welsh, D.M.; Morvant, M.C.; Piroux, F.; Abboud, K.A.; Reynolds, J.R. Conducting Poly (3,4-alkylenedioxythiophene) Derivatives as Fast Electrochromics with High-Contrast Ratios. Chem. Mater. 1998, 10, 896-902. [CrossRef]

15. Rendón-Enríquez, I.N.; Scherf, U.; Tausch, W.M. Elektrochrome Fenster. Chem. Shule 2016, 65, 34-39.

16. Rendón-Enríquez, I.N.; Tausch, M.W.; Scherf, U. Elektrochrome Fenster mit Leitenden Polymeren. Chem. Unserer Zeit 2016, 50, 400-405. [CrossRef] 
17. Inzelt, G. Recent Advances in the Field of Conducting Polymers. J. Solid State Electrochem. 2017, 21, $1965-1975$. [CrossRef]

18. Palma-Cando, A.U.; Frontana-Uribe, B.A.; Maldonado, J.L.; Hernández, M.R. Control of Thickness of PEDOT Electrodeposits on Glass/ITO Electrodes from Organic Solutions and its Use as Anode in Organic Solar Cells. Procedia Chem. 2014, 12, 92-99. [CrossRef]

19. Piron, F.; Leriche, P.; Grosu, I.; Roncali, J. Electropolymerizable 3D $\pi$-Conjugated Architectures with Ethylenedioxythiophene (EDOT) End-Groups as Precursors of Electroactive Conjugated Networks. J. Mater. Chem. 2010, 20, 10260-10268. [CrossRef]

20. Palma-Cando, A.; Scherf, U. Electrochemically Generated Thin Films of Microporous Polymer Networks: Synthesis, Properties, and Applications. Macromol. Chem. Phys. 2016, 217, 827-841. [CrossRef]

21. Suresh, V.M.; Scherf, U. Electrochemically Generated Conjugated Microporous Polymer Network Thin Films for Chemical Sensor Applications. Macromol. Chem. Phys. 2018, 219, 1800207. [CrossRef]

22. Bildirir, H.; Gregoriou, V.G.; Avgeropoulos, A.; Scherf, U.; Chochos, C.L. Porous Organic Polymers as Emerging New Materials for Organic Photovoltaic Applications: Current Status and Future Challenges. Mater. Horiz. 2017, 4, 546-556. [CrossRef]

23. Bildirir, H.; Osken, I.; Ozturk, T.; Thomas, A. Reversible Doping of a Dithienothiophene-Based Conjugated Microporous Polymer. Chem. Eur. J. 2015, 21, 9306-9311. [CrossRef]

24. Gu, C.; Chen, Y.; Zhang, Z.; Xue, S.; Sun, S.; Zhang, K.; Zhong, C.; Zhang, H.; Pan, Y.; Lv, Y.; et al. Electrochemical Route to Fabricate Film-Like Conjugated Microporous Polymers and Application for Organic Electronics. Adv. Mater. 2013, 25, 3443-3448. [CrossRef]

25. Palma-Cando, A.; Scherf, U. Electrogenerated Thin Films of Microporous Polymer Networks with Remarkably Increased Electrochemical Response to Nitroaromatic Analytes. ACS Appl. Mater. Interfaces 2015, 7, 11127-11133. [CrossRef]

26. Gu, C.; Huang, N.; Chen, Y.; Qin, L.; Xu, H.; Zhang, S.; Li, F.; Ma, Y.; Jiang, D. $\pi$-Conjugated Microporous Polymer Films: Designed Synthesis, Conducting Properties, and Photoenergy Conversions. Angew. Chem. 2015, 127, 13798-13802. [CrossRef]

27. Palma-Cando, A.; Brunklaus, G.; Scherf, U. Thiophene-Based Microporous Polymer Networks via Chemical or Electrochemical Oxidative Coupling. Macromolecules 2015, 48, 6816-6824. [CrossRef]

28. Palma-Cando, A.; Woitassek, D.; Brunklaus, G.; Scherf, U. Luminescent Tetraphenylethene-Cored, Carbazoleand Thiophene-Based Microporous Polymer Films for the Chemosensing of Nitroaromatic Analytes. Mater. Chem. Front. 2017, 1, 1118-1124. [CrossRef]

29. Palma-Cando, A.; Preis, E.; Scherf, U. Silicon- or Carbon-Cored Multifunctional Carbazolyl Monomers for the Electrochemical Generation of Microporous Polymer Films. Macromolecules 2016, 49, 8041-8047. [CrossRef]

30. Räupke, A.; Palma-Cando, A.; Shkura, E.; Teckhausen, P.; Polywka, A.; Görrn, P.; Scherf, U.; Riedl, T. Highly Sensitive Gas-Phase Explosive Detection by Luminescent Microporous Polymer Networks. Sci. Rep. 2016, 6, 29118. [CrossRef]

31. Zhang, Q.; Dong, H.; Hu, W. Electrochemical Polymerization for Two-Dimensional Conjugated Polymers. J. Mater. Chem. C 2018, 6, 10672-10686. [CrossRef]

32. Molapo, M.K.; Ndangili, M.P.; Ajayi, F.R.; Mbambisa, G.; Milu, M.S.; Njomo, N.; Masikini, M.; Baker, P.; Iwuoha, I.E. Electronics of Conjugated Polymers (I): Polyaniline. Int. J. Electrochem. Sci. 2012, 7, 11859-11875.

33. Genies, E.M.; Lapkowski, M. Spectroelectrochemical Study of Polyaniline versus Potential in the Equilibrium State. J. Electroanal. Chem. Interfacial Electrochem. 1987, 220, 67-82. [CrossRef]

34. Geniès, E.M.; Lapkowski, M.; Penneau, J.F. Cyclic Voltammetry of Polyaniline: Interpretation of the Middle Peak. J. Electroanal. Chem. Interfacial Electrochem. 1988, 249, 97-107. [CrossRef]

35. Zotti, G.; Cattarin, S.; Comisso, N. Electrodeposition of polythiophene, polypyrrole and polyaniline by the cyclic potential sweep method. J. Electroanal. Chem. Interfacial Electrochem. 1987, 235, 259-273. [CrossRef]

36. Funt, B.L.; Lowen, S.V. Mechanistic Studies of the Electropolymerization of 2,2'-bithiophene and of Pyrrole to form Conducting PSolymers. Synth. Met. 1985, 11, 129-137. [CrossRef]

37. Atwani, O.; Baristiran, C.; Erden, A.; Sonmez, G. A stable, low band gap electroactive polymer: Poly(4,7-dithien-2-yl-2,1,3-benzothiadiazole). Synth. Met. 2008, 158, 83-89. [CrossRef]

38. Heinze, J. Electrochemistry IV. In Topics in Current Chemistry; Steckhan, E., Ed.; Springer: Berlin, Germany, 1990.

39. Inzelt, G. Role of polymeric properties in the electrochemical behaviour of redox polymer-modified electrodes. Electrochim. Acta 1989, 34, 83-91. [CrossRef] 
40. Wallace, G.G.; Spinks, G.M.; Kane-Maguire, L.A.P.; Teasdale, P.R. Conductive Electroactive Polymers, 3rd ed.; CRC Press Taylor \& Francis Group: Boca Raton, FL, USA, 2009.

41. Huang, W.S.; MacDiarmid, A.G. Optical properties of polyaniline. Polymer 1993, 34, 1833-1845. [CrossRef]

42. Monk, P.M.A.; Mortimer, R.J.; Rosseinsky, D.R. Electrochromism and Electrochromic Devices; Cambridge University Press: New York, NY, USA, 2007.

43. Ding, Y.; Invernale, M.A.; Mamangun, D.M.D.; Kumar, A.; Sotzing, G.A. A Simple, Low Waste and Versatile Procedure to make Polymer Electrochromic Devices. J. Mater. Chem. 2011, 21, 11873-11878. [CrossRef]

44. Ambrose, J.F.; Nelson, R.F. Anodic Oxidation Pathways of Carbazoles: I. Carbazole and N-Substituted Derivatives. J. Electrochem. Soc. 1968, 115, 1159-1164. [CrossRef]

45. Yu, T.; Wu, X.; Lv, Y.; Liu, L.; Du, L.; Zhou, J.; Xie, Z.; Ma, Y. An Electrochemically Deposited Film as an Interface Layer to Improve the Performance of Polymer Light-Emitting Diodes. J. Mater. Chem. C 2014, 2, 4117-4120. [CrossRef]

46. Mothika, V.S.; Räupke, A.; Brinkmann, K.O.; Riedl, T.; Brunklaus, G.; Scherf, U. Nanometer-Thick Conjugated Microporous Polymer Films for Selective and Sensitive Vapor-Phase TNT Detection. ACS Appl. Nano Mater. 2018, 1, 6483-6492. [CrossRef]

47. Salinas, G.; Del-Oso, J.-A.; Espinoza-Montero, P.-J.; Heinze, J.; Frontana-Uribe, B.A. Electrochemical Polymerization, Characterization and in-situ Conductivity Studies of Poly-3,4-ortho-xylendioxythiophene (PXDOT). Synth. Met. 2018, 245, 135-143. [CrossRef]

48. Inzelt, G. Electrochemical Quartz Crystal Microbalance. In Electrochemical Dictionary, 1st ed.; Bard, A.J., Inzelt, G., Scholz, F., Eds.; Springer: Berlin, Germany, 2008; p. 723.

49. Sauerbrey, G. Use of Quartz Vibration for Weighing Thin Films on a Microbalance. J. Phys. 1959, 155, $206-212$.

50. Weidlich, C.; Mangold, K.M.; Jüttner, K. EQCM Study of the Ion Exchange Behaviour of Polypyrrole with Different Counterions in Different Electrolytes. Electrochim. Acta 2005, 50, 1547-1552. [CrossRef]

51. Sing, K.S.W. Reporting Physisorption Data for Gas/Solid Systems with Special Reference to the Determination of Surface Area and Porosity (Recommendations 1984). Pure Appl. Chem. 1985, 57, 603-619. [CrossRef]

52. Chen, Q.; Luo, M.; Hammershøj, P.; Zhou, D.; Han, Y.; Laursen, B.W.; Yan, C.-G.; Han, B.-H. Microporous Polycarbazole with High Specific Surface Area for Gas Storage and Separation. J. Am. Chem. Soc. 2012, 134, 6084-6087. [CrossRef]

53. Laviron, E.; Meunier-Prest, R.; Vallat, A.; Roullier, L.; Lacasse, R. The Reduction Mechanism of Aromatic Nitro Compounds in Aqueous Medium: Part II. The Reduction of 4-nitropyridine Between H0 = -6 and pH 9.6. J. Electroanal. Chem. 1992, 341, 227-255. [CrossRef]

54. Bai, S.; Hu, Q.; Zeng, Q.; Wang, M.; Wang, L. Variations in Surface Morphologies, Properties, and Electrochemical Responses to Nitro-Analyte by Controlled Electropolymerization of Thiophene Derivatives. ACS Appl. Mater. Interfaces 2018, 10, 11319-11327. [CrossRef] 